Article

\title{
Science-sustainability Transformational Paradox: An Interdisciplinary and Inter-Institutional Analysis
}

\author{
Tariq H. Malik ${ }^{1}$, and Huo Chunhui 1,2* \\ 1 International Centre for Organisation and Innovation Studies \\ Liaoning University Business School; t.h.malik@lnu.edu.cn \\ 2 Research Center for the Economies and Politics of Transitional Countries; huoch@lnu.edu.cn \\ * Correspondence: huoch@lnu.edu.cn; Tel.: +86-186-4004-2752
}

\begin{abstract}
The Science-Sustainability poses an interdisciplinary paradox. On the one hand, the science for sustainability has increased in OECD economies particularly in China and US; on the other hand, the sustainability situation has worsened ( $\mathrm{Co} 2$ emission has risen). The adverse correlation shows a paradox. However, without explicating the science-sustainability relationship, it leads to a premature conclusion. In this study, we have drawn on three concrete questions for concrete answers. First, whether and how interdisciplinary sciences-energy science and environmental science-contribute to the sustainability. Second, whether and how the Sino-US inter-institutional analysis varies in the science-sustainability paradox. The empirical analysis from a panel data in the interdisciplinary and inter-institutional context show mixed patterns in three ways. First, the increase in the environmental science shows an improvement in the sustainability; the energy science shows a decline in the sustainability. Second, the Chinese environmental science has a comparative advantage to American environment science for the sustainability development, and the Chinese energy science has a comparative disadvantage to the US in the sustainability development. Third, the environmental science mediates the energy science in the science-sustainability relationships. Standing alone, the increase in the energy science harms sustainability; mediated by environmental science, it benefits sustainability. The study explains the adverse role of energy science in Jevons Paradox. The study also offers some policy paths for further research how capitalisms differently innovate, form strategies, and implement the practice.
\end{abstract}

Keywords: Chinese National science-sustainability paradox; Interdisciplinary and inter-institutional analysis; Environmental science mediating the energy science for sustainability; Chinese environmental science versus the American energy science.

\section{Introduction}

The deteriorating quality of the natural environment strikes a science-sustainability paradox in the context of Sino-US scientific discoveries energy and environmental publications. In the energy science discipline, China produces more scientific publication than the US; in the environmental science discipline, the US produces more publications than China. Because China outperforms in energy science and the US in environmental science publications, the Chinese codified knowledge in the energy science discipline should reduce the Co2 emission more than the US; the US codified knowledge in the environmental science discipline should reduce the national $\mathrm{Co} 2 \mathrm{emission}$ more than China. However, both China and the US produce more Co2 emission than any other economy. Together, China and the US contribute to such that the global Co2 emission has unexpectedly increased. Appendix A shows the rise of Co2 emission in 2017. Furthermore, Appendices B and C show the change from 1996 to 2016 in China and the USA. China is changing rapidly in 
performance and institutions behind it (Storz, Amable, Casper, \& Lechevalier, 2013). This science-sustainability paradox supplies a contextual opportunity, in conjunction with interdisciplinary science, for the analysis two comparative capitalisms (Boyer, 2005, 2008).

The comparative analysts on the capitalism distinguish between the US's liberal economy and the Chinese state economy. Indeed, the US liberal entrepreneurial economy (LEE) relies on markets, claims efficient resource allocation, and constraints opportunistic behaviour in the economic activity. We also know that the Chinese state entrepreneurial economy (SEE) relies on national, regional, or local state authorities interventions in the economic adjustments (Boyer, 1996). Henceforth, we refer the former type to LEE capitalism in the interdisciplinary transformation of science (Vallas \& Kleinman, 2008), and the latter type to SEE capitalism to the transformation of national science and sustainability. The literature explains that the market activities support the LEE capitalism in knowledge creation to its economic exploitation. In these market activities, individual and private enterprises make independent decisions in the science-sustainability relations (Storz et al., 2013). On the opposite, the state's entrepreneurial decisions support the SEE capitalism in knowledge creation to its exploitation (Duckett, 1996; Eisinger, 1988; Mazzucato, 2014; Tiberghien, 2007). Moreover, the economies from both sides of the spectrum show unequivocal roles in the science-sustainability link - a paradoxical effect (Sorrell, 2009). These ambiguities suggest institutional variation in comparative capitalism argument how inter-disciplinary development (energy versus environmental sciences) depends on the inter-institutional (LEE versus SEE) understanding.

Without inter-institutional analysis between LEE and SEE and how they transform national sciences for Co2 emission, blaming China, or the US misses the broader point. We draw on the conceptual hierarchy of institutional concepts (Hollingsworth, 2003). This hierarchical structural difference between the two types of capital informs us about different structures and processes. Second, like the analysis of LEE versus SEE, Chinese Science-Sustainability paradox merits focused attention. Currently, most writer target the Chinese Co2 emission and environmental degradation (Gan, 1998; Schweizer-Ries, 2008;Liu, Lyu, Pan, \& Wang, 2017; Du, \& Yang,2017; Zhang, Winchester, \& Zhang, 2017a; Zhang, Peng, Chao-Qun, \& Shen, 2017b; Chen, \& Yan, 2018; Yan, Yi, Qiu \& Yang, 2018). Since China receives scientific glory as well as environmental blame (Lancet, 2017), we find it necessary that the inter-disciplinary comparison within the SEE explored because of international diversity of sub-systems (Storz et al., 2013). Second, the current literature overwhelmingly examines the stability and change in the Western types of capitalism; it neglects the combination of stability and rapid change in China (Storz et al., 2013). Naturally, the current literature lacks specific analysis of the inter-disciplinary analysis between energy science and environmental science as contributors to sustainability - a type of innovation performance (Storz et al., 2013). The mediating or moderating role of one or the other discipline merits focused analysis in this juxtaposition between the two disciplines transform knowledge form discoveries to exploitation (Etzkowitz, 2003). Third, the intra-disciplinary analysis merits attention some technological discoveries increase the energy consumption (Jevons, 1866). The inter-institutional, inter-disciplinary and intra-disciplinary analyses address the Chinese Science-sustainability issue for socio-economic development (Anand \& Sen, 2000, p2030) and avoid the bleak policy scenario of Jevons Paradox (Jevons, 1866).

In his Paradox, the British economist, Stanley Jevons, argues that technological development increases rather than decreases the consumption of coal, and his argument resonates with the paradox today. In Jevons time (Jevons, 1866), the threat of depletion of coal concerned policymaker of the industrial revolution, and the policymakers believed that technological development increases efficiencies and decreases the energy consumption-the coal. Jevons suggested that technological efficiencies make resources cheaper, leading to the increase in their demand and inducing economic growth. Economic growth further increases the demand for energy resources, leading to the increase in energy consumption. As a result, the technological development produces perverse effects on the energy saving and sustainability. Since the Jevons paradox resonates with 
the science-sustainability paradox today, the inter-institutional, inter-disciplinary and intra-disciplinary evidence find a rationalised place in the current argument in the policies of the liberal market in the US and entrepreneurial state in China in a focused analysis.

The focused analysis limits its scope to the Chinese Science-sustainability in comparison to the US for two reasons. Firstly, the LEE of the US follows clear and coherent institutional development (Hall \& Soskice, 2001). The SEE follows incoherent institutional systems, and yet it has performed in the economic growth (Storz et al., 2013). Secondly, the prior literature explains that the economic growth contributes to social development (sustainability) through directed policies (Deaton, 2013; Sen, Stiglitz, \& Fitoussi, 2010). Without the directed policies, the GDP growth increases and sustainability and social development decreases. Thirdly, the literature on economic policy raises questions about the social development in conjunction with the economic growth (Sen et al., 2010). Most economies seek science-economic growth path (Storz et al., 2013), neglecting the science-sustainability path or political stability (Boyer, 2011). Between the science-growth and stability, the middle path of science-sustainability raises empirical questions in the inter-capitalism and interdisciplinary analysis.

Does the inter-disciplinary interaction explain the Chinese science-sustainably dilemma? We develop the inter-institutional comparison between LEE capitalism and SEE capitalism, and then we turn to the inter-disciplinary between the two capitalisms.

\section{Framework}

Sustainability

The concept of sustainability differs between people. Some scholars combine environment (Anand \& Sen, 2000) with economic sustainability through social development in their writings. The notion of social development, sometimes interchangeably used with poverty and inequality reduction in the writings of Noble Laureate economist, Amartya Sen (Sen, 1985). Most recently, another Noble Laureate economist, Angus Deaton, adds the healthcare improvement in the broader concept of social developed (Deaton, 2013). The world bank includes the environment, equality, poverty reduction and healthcare in the notion of the social development (WB, 2016). Since these constituents make up the concept of social development in the economic development discourse, and the social development often appears interchangeable with the notion of sustainability, the inclusion of these economic constituents delimits the concept of sustainability.

We limit the scope of the concept to environmental sustainability because it has become a salient issue in the world today. One reason suggests that environmental sustainability takes the precedent because it hurts the developing and developed countries without discrimination. Second, the environmental quality deteriorates at increasing rates in every passing day. Third, the increasing interest in economic growth around the world increases the energy consumption (fossil fuel and chemical). Fourth, China and the US lead in the Co2 emission. At the same time, they lead in economic growth. Since the energy sources cause the $\mathrm{Co} 2$ emission in the world and the $\mathrm{Co} 2$ in the air accounts for the declining quality of the natural environment, we focus on the sustainability of the environment in the Sino-US comparison on policy and practice.

The policy and practice of the US vis-à-vis China pose a paradox. On the one hand, the US and China have become the leading economic powers; on the other hand, they lead in the scientific discoveries and publications. Since the science and technology increase increases economic growth, it should improve environmental sustainability. Although the science-growth link gains legitimate status, the science-sustainability link lags in this level of legitimacy. However, the national science-based productivity of the two leading economies continuously improves; the environment quality continues to worsen (Lancet, 2017). Both economies take the blame, and most popular writings and commentators single China out as the main polluter through the Co2 emission. Sometimes alone and sometimes in the Sino-US comparison, China faces the science-sustainability paradox directly or indirectly in academic and popular literature. 
Although the science-sustainability phenomenon entered the intellectual discourse in the 1970s (Meadows, Meadows, Randers, \& Behrens III, 1972), it gained momentum in recent writings (Sen et al., 2010). Some writers content on one path to the science-sustainability to resolve the paradox; other writers content on two paths to the paradox solution. In this two-path solution, one refers to the interdisciplinary path of science; the other path refers to the inter-institutional development path. The inter-institutional perspective focuses on the national level integrated institutions. For instance, the current US president in 2017 and some American scientists disagree that the human intervention and industrial activity causes fossil fuel-based Co2 emission behind the environmental degradation. In contrast, capitalisms that subscribe to the Kyoto protocols contend that the human intervention and conventional energy form the Co2 emission causes $n$. Overall, most of the world agrees that the environment had degraded to a critical point.

Social scientists offer the sustainability solution through two forms of capitalism to explain science-sustainability proposition. One type of capitalism rests on the free market logic; the other type of capitalism rests on the entrepreneurial state intervention. The free market view calls its liberal entrepreneurial economy (LEE), and the state-driven camp calls it state entrepreneurial economy (SEE). The proponents of LEE side continue to follow Milton Friedman's (1962, p11) enduring argument, in which he argues: "The great advances of civilisation, whether in architecture or painting, science or literature, industry or agriculture, have never come from centralised government". Moreover, the LEE camp continues to ridicule the SEE argument despite all its weakness and failures to address sustainability. For instance, the LEE follows common economic indicators to highlight economic growth but ignores the social contract and stability of the system (Boyer, 2005, 2008).

The proponents of the SEE capitalism support the Karl Polanyi's great transformation (Polanyi, 1944). Most recently, the support for the SEE argument gaining momentum in regulation theory (Boyer, 2011) and comparative institutions (Block \& Keller, 2009; Block \& Somers, 2014; Campbell, 2011; Kenworthy, 2006). Like the LEE capitalism, the SEE capitalism shows a positive link between science and economic development (Storz et al., 2013), both types of capitalism supporting the science-growth transformation. However, they become dissimilar in the transformation of their national sciences into sustainability. On the one hand, the transformational relationship between energy science and sustainability is unclear from the LEE versus SEE perspectives. On the other hand, the transformational relationship between environmental science and sustainability is unclear between the two comparative types of capitalism. We know the institutional differences between LEE and SEE but not their effectiveness in the creation and application of science for the environmental improvement.

The answer depends on the inter-institutional and inter-disciplinary in LEE and SEE comparison. The institutional argument examines capitalisms from the structural perspectives or behavioural perspectives. The structural perspective defines institutions as rules of the game (North, 1990). The behavioural perspective defines institutions as the behaviour of the actors who deal with the rules of the game (Schotter, 1981). We adopt the integrative approach of the structural and behavioural institutions because national institutions create and transform national science for sustainability through structural and behavioural policy and practice (Hollingsworth, 2003). These integrated roles between systems of knowledge and system of institutions explain the science for economic growth as well as for sustainability (Deaton, 2013; Sen et al., 2010). Thus, science-sustainability proposition rests on the structural and behavioural differences within and between capitalism.

In the following, we discuss the science-sustainability proposition. In doing so, we differentiate between the theoretical and empirical links between energy science and environmental science. Then we will address the institutional role that integrated the two disciplines. Then we show the structure of the integration-the argument that environmental science mediates the energy science. 
National science: energy and environmental

Inter-disciplinary national science in the current context refers to energy and environmental science disciplines, and these disciplines directly and interactively contribute to the Co2 emission through different transformative paths.

The science transforms into technology through two vertical paths for final artefacts. One path leads to economic growth without sustainability, and the other path leads to sustainability without economic growth. Either path alone rests on the distributive logic. The distributive perspective suggests that the individuals, organisations, and national institutions compete for their interests. It means that the one distributive perspective survives at the cost of the other distributive perspective. For instance, the economic growth comes at the cost of environmental loss. The two paths together form the integrative perspective (Garud \& Karnøe, 2003), and this integrative perspective accommodates the growth and sustainability. Figure 1 depicts these paths to elaborate their distributive and integrative orientations and consequences.

The orientation of the distributive perspective lies in the energy science in the interdisciplinary comparison, which leads to economic growth. The orientation of the integrative perspective lies in the environmental science, which leads to sustainability. Unlike the distributive perspective, the economic growth brings positive implications for sustainability, and sustainability brings varying implications for economic growth. This middle path in Figure 1 depicts the integrative perspective, its orientation and consequences at the discipline level and institution level. At the discipline level, integration of energy and environment sciences explain the variance in the sustainability. At the national institutions level, the inter-institutional capitalism perspective explains the support for the flow of science towards the outcome. In a simplified parallel view, the lenses of LEE capitalism explain the comparative position of the US and the lenses of SEE capitalism explain the comparative position of China in the science-sustainability path.

Insert Figure 1 about here

The scientific knowledge perspective in the context of science-sustainability relationships depends on ease of transformation of knowledge from the discovery to exploitation for economic development and social development. The discovery of science displays two dimensions of knowledge: the explicit and tacit (Polanyi, 1967). The explicit knowledge producers codify to transform and deploy it across contexts. In contrast, the tacit knowledge producers contextualise it to keep it organisation-specific. In other words, the explicit knowledge flows independent of the context; the tacit knowledge flows through interactive processes and interpretation (March, 1999). In short, the codified knowledge flows within and between organisations without a loss; the tacit knowledge flows through interaction and socialisation between entities at the personal, organisational, and national levels. Together, both affect and reflect each other. The explicit knowledge increases tacit knowledge through practice, and the tacit knowledge increases explicit through new combinations. For instance, the interpersonal, inter-contextual, and inter-structural interactions for the translate one type of knowledge to the other type.

For our purpose, codified knowledge suits to assess the link between national science and sustainability for several reasons. Firstly, the codified knowledge in national publications is context-free, and for this quality, codified knowledge become reliable data. Secondly, the reliable data need to be measurable. The publication count in a discipline at a national level meets this condition. Thirdly, the reliable data need to be accessible to evaluators. Scientific publications exist in the public domain. The access to private knowledge is difficult and costly; the access to scientific publications is easy and economical. Especially for quantitative studies, the data are free on any publications. Fourthly, the codified knowledge is transferable within and between organisations in the national setting. Therefore, the transformed national knowledge to artefacts depends on the national bricolage. 
The national bricolage transforms the codified national science into artefacts because it provides contextual interpretation in policy and practice at the organisational and national level (March, 1999). The bricolage occurs when distributive elements of national knowledge interaction to form a new path in the sector (Garud \& Karnøe, 2003). The emergence of the new path that then becomes the driving mechanism for the behavioural patterns of the sector and related national institutions. This principle of combining multiple existing resources and policies that form a new structure in a bricolage advance the transformation of knowledge from discoveries to technological artefacts (Douglas, 1986; Duymedjian \& Ruling, 2010; Levi-Strauss, 1966; Stinchfield, Nelson, \& Wood, 2013). Bricoleurs such as organisations, national agencies and networks provide interactive context.

The bricolage also occurs in the interaction between policy and practice for creating meaning at the organisation and national (Campbell, 2001; Di Domenico, Haugh, \& Tracey, 2010). Since the national level bricolage and interpretation of knowledge become the basic tenets of the principles of knowledge creation, development and application in the interpreted context (March, 2014). The transformation of the national science into national technology for sustainability rests on the meaning of national institutions of capitalism that support those meanings.

The bricolage of resources, actors and structures generate a new context that changes the meaning. A typical context forms one or some combination of the five factors. One factor captures the functional attributes of the entity in the bricolage. The other factor captures the location or social space in the bricolage (Giddens, 1991). The third factor captures actors in the bricolage-individuals, organisational or national. The fourth factor captures temporality, and temporality falls on the kinematic view or the social view of time in the capitalism (Boyer, 2011). The last factor that forms the context for meaning captures structures or methods. These structures support procedures, processes, and practice. According to these attributes, national institutions exemplify the structural support that creates and transform national knowledge. Since national institutional bricolage differs across capitalism, the paths of interaction in the bricolage will differ.

We theorise the vertical transformation of national science into sustainability in distributive and the integrative part through the mediation between the two: energy science and environmental science. Figure 2 shows a visual representation of the interdisciplinary and inter-institutional paths for comparative analysis. A visualised theorising helps in understanding the intricacies of complex ideas and their structures (Swedberg, 2014). On the left side, the two scientific disciplines flow in distributive fashion-either to economic growth or sustainability-or integrative fashion to both-economic growth and sustainability. The first path aligns with national energy science, and the other path aligns with the environmental science. The national energy science as an input to economic growth increases $\mathrm{Co} 2$ emission because it increases the demand for energy, and it decreases the $\mathrm{Co} 2$ emission when it contributes to low consumption of energy - a phenomenon relates to the Jevons Paradox.

According to Jevons Paradox, the energy science and technology increase energy consumption because it fuels the industrial growth (Jevons, 1866). The environmental science supports sustainability by offering low consumption mechanism before the economic activity and after the economic activity related to the transaction of artefacts. In the earlier stage, the environmental science manages the residual of the energy infused in the air, and in the later stage, it offers an integrative solution. If these two distributive paths hold, then the direct effect of the energy science fosters economic growth but harms the environment, and the indirect effect of environment serves sustainability but reduces economic growth.

To draw the benefit of both worlds of disciplines and institutions behind them, we propose that the environmental science mediates the energy science in the science-sustainability relations to form the integrative path. In this proposition, two assumptions underlie the mediation effect. First, the energy science precedes environment in the sustainability question. Second, the economic actors pursuing energy science far exceed those economic actors seeking environment science. According 
to these assumptions, we exclude the moderation effects of environment science and mediation effects of the energy science in the argument of science-sustainability.

The environmental science mediates rather than energy science mediates. Four analytical conditions support the mediation effect in favour of environmental science. Firstly, on the timeline in the vertical industrial value chain, the energy comes as input in the process, and environment comes as the output. The energy science borders with input, and it seeks output efficiencies within a specific domain. The environmental science borders with the context of multiple functions, actors and structures in the social network system in a broader national domain (Merrill \& Sintov, 2016; Schweizer-Ries, 2008). Moreover, energy science develops in a lab experiment; the environmental science develops in field experiments. Whereas the field experiment occurs closer to the real world of sustainability, the energy science experiment occurs at the beginning of idea-value chain - distal from the environment. Second, the energy science rests on the content of knowledge. It includes discoveries, efficiencies, and effectiveness of the science. The environmental science rests on the scientific and social structures. In principle, the environmental science bridges the link between the need for energy and the new for environmental quality - sustainability. Third, the environmental science encapsulates a broader range of knowledge types, stakeholders, resources, and conditions than the energy science. For example, at the discipline level, environmental science consists of 12 subdisciplines and energy science consists of five subdisciplines. Moreover, the environmental science includes distal disciplines; the energy science includes proximal disciplines. Since the temporal, spatial, intellectual, and structural position of the environmental science shows as an enabling factor, we use it as the mediator between the energy science and sustainability in the development of a hypothesis.

The energy science will negatively affect sustainability because it increases the Co2 emission, and the $\mathrm{Co} 2$ emission harms the natural environment, leading to its adverse effects on health, food safety and general degradation. Although researchers show that energy science and environmental science decrease the Co2 emission in China over time (Zhang et al., 2017b), they miss the inter-disciplinary link and inter-institutional links for Sino-US comparison. This study starts from this missing point. At the interdisciplinary level, taking the Jevons Paradox (Jevons, 1866), we assess that the energy science leads to the $\mathrm{Co} 2$ emission for good reasons. Firstly, energy science increases demand for energy and its consumption. Here, the concept of energy science refers to conventional energy sources and their efficient production and usage. According to the paradox, the energy development (science) increases its consumption in two ways. One way it increases because it becomes cheap and efficient. The second way it increases because it fuels the industrial growth. The economic growth means more energy demand, which is an exogenous factor in the Co2 emission (Zhang et al., 2017a). If these assumption hold, then the energy science and its development will lead to the increase in the $\mathrm{Co} 2$ emission. The direct link in Figure 2 shows this hypothesis.

Hypothesis 1: National energy science will positively correlate with the national Co2 emission

The environmental science mediates rather than energy science mediates. Four analytical conditions support the mediation effect in favour of environmental science. Firstly, on the timeline in the vertical industrial value chain, the energy comes as input in the process, and environment comes as the output. As noted before, the energy science borders with the input and the environmental science borders with the society. Energy science develops in a lab experiment; the environmental science develops in field experiments. Whereas the field experiment occurs closer to the real world of sustainability, the energy science discoveries and development takes place in the early stages. Second, the energy science rests on the content of knowledge. It includes discoveries, efficiencies, and effectiveness of the science. The environmental science rests on the scientific and social structures. In principle, the environmental science bridges the link between the need for energy and the new for environmental quality - sustainability. Third, the environmental science 
includes distal components of knowledge that includes biological sciences, natural sciences, and social sciences. Moreover, the environmental science includes distal disciplines; the energy science includes proximal disciplines. Since the temporal, spatial, intellectual, and structural position of the environmental science shows as an enabling factor, we use it as the mediator between the energy science and sustainability in the development of a hypothesis.

Hypothesis 2: National environment science will mediate the national energy science in the national $\mathrm{Co} 2$ emission

Hypothesis 2: National environment science will negatively correlate with the national Co2 emission

Chinese versus US science-sustainability

The LEE (liberal entrepreneurial economy) and SEE (state entrepreneurial economy) types of capitalisms in the literature have become the hallmark of the discourse in the last two decades (Duckett, 1996; Eisinger, 1988; Tiberghien, 2007).

The preceding hypotheses show direct and mediating effects of environmental science on sustainability. One assumption implies unchanged national institutions transform the energy science into economic growth, increasing the $\mathrm{Co} 2$ emission. Contrary to the energy science, the other assumption implies that unchanged national institutions transform the national science to decrease the $\mathrm{Co} 2$ emission. In contrast to the distributive role of energy versus environmental science, which foster economic growth or environmental quality, the combination of the two offers an integrative solution when the environmental science mediates the energy science in the transformation process. Accordingly, this integrative logic and order, the direct and interaction effects of the two related sciences produce testable hypotheses, and these hypotheses give empirical possibilities to support an inter-disciplinary comparison and inter-interinstitutional comparison within the direct and mediating effects.

The inter-institutional comparison in the comparative capitalism argument relies on multiple streams. One stream links the national innovation system to the exploration and exploitation of science to economic productivity (Freeman, 2002). Another stream links university-industry relations to support interactive learning at the national level for the exploration and exploitation of national science (Lundvall, Johnson, Andersen, \& Dalum, 2002; Von Hippel, 1988). The university-industry knowledge depends on the linear flow of science to products, the backward linear, mediated between university and industry through venture capital, incubators, and other institutional mechanisms (Etzkowitz, 2003). Compared to these national innovation system scholars, institutionalists argue about the rules of the game at the macro level (North, 1981) or actors's behaviours towards the rules of the game (Schotter, 1981) at multiple levels of an economy. In an integrative view of these types and of institutions and behaviours of actors, a multiple level analysis of the institutions explains the change and stability (Hollingsworth, 2003). This view aligns with the regulatory perspective of the comparative capitalism (Boyer, 2005, 2011). Following the integrative view of the institutional stability and change, we address the neglected role of the entrepreneurial state in the capitalism comparative capitalism in China (Storz et al., 2013) by contrasting it with the liberal capitalism in the USA.

Following our earlier note, the types of contrasting capitalism in the comparative capitalism argument raise alternative options. On the one hand, similar institutional policy leads to different paths and outcomes in the science-sustainability relationship. The US capitalism rests on the liberal market entrepreneurial structure, and the Chinese capitalism rests on the state entrepreneurial institutional structure. The liberal entrepreneurial economy (LEE) in the US economy and the state entrepreneurial economy (SEE) in China differently affect and reflect the science-sustainability path. For instance, the LEE and SEE produce similar knowledge systems in the university, scientific 
publication and patents, and yet they differ in the transformation path and outcome. On the other hand, different institutional policies lead to similar outcomes in the science-sustainability relationships. For instance, the LEE and SEE unequivocally differ in the types of capitalism, and yet they strongly contribute to the science and economic growth in GDP.

Five elements define characteristics of the LEE capitalism and SEE capitalism for the national science transformation for sustainability (Boyer, 2004). First refers to the labour relations. The second refers to the form of competition. The third refers to monetary regimes. The fourth refers to the role the of the state vis-à-vis the economy. The fifth refers to international business context. These constituent parts of capitalism rest on the regulation theory that assumes a historical path of an economy and any point on that path holds a diversity of constituent factors (Boyer, 2011). The regulatory theory addresses multiple levels (Hollingsworth, 2003; Storz et al., 2013) compared to the limited focus of macro institutions at the political level (North, 1990) or the varieties of the institution at the production unit level (Hall \& Soskice, 2001).

The variety argument relies on four constituents of capitalism that supports the economic growth through the innovation at the firm level. First, corporate governance (relations between firms and investors) and institutions shape the capitalism. Second, inter-firm interaction and relation shape the input-put transaction of resources define the capitalism. The legal system and the network structures form this part of comparative capitalism. Third, the nature of labour skills and the wages determination make the third part of comparative capitalism. Fourth, the financing mechanisms, such as equity, private investment, or state investment decision form the last component of comparative capitalism (Hall \& Soskice, 2001). The five components of regulation theory and comparative capitalism overlap in most factors in substance or context. However, the regulation theory suggests that the alternative approaches ignore maintenance of the social contract and the sustainability of the system. They also ignore the sustainability performance as the indicator of the national economy. Since the science-sustainability proposition supports the integration between the economic performance and sustainability, we draw comparable patterns between the LEE and SEE.

In a generic view, both sides differ on several comparable measures. First, the market forces in the US influences the structure and behaviour of the economic entities; the state authority influences the structure and behaviour of the economic entities in China. Second, historical paths and punctuations on that path differ in intensity, quality, and implications in China (Aoki, 2013). Third, the Chinese system flows top-down information for the entrepreneurship, and the US system flows bottom-up information for the entrepreneurial activity. Fourth, the Chinese perspective on the time span involves long-term policies; the US perspective follows a short-term time span in the economic activity. The Chinese practice and policy draw cues from the social context; the US practice to follow the policy draws cues from the contractual context. The temporal context in China reflects historical interpretation; the temporal context in the US reflects kinematic interpretation (Boyer, 2011). The kinematic interpretation commodifies time, and the social interpretation experiences the time (Giddens, 1991). The differential attributes separate them into two systems: the LEE of the US and SEE of China for comparative analysis.

The Sino-US inter-institutional comparison for the analysis of science-sustainability paradox forms the first natural step in the analysis. As noted in the above, the Chinese capitalism (SEE) hosts incoherent institutions and shows rapid change (Storz et al., 2013) compared to the LEE capitalism of the US. The LEE in the US builds on microeconomic logic, policies, and practice. The SEE in China builds on macroeconomic logic, policies, and practice. The LEE leads the OECD club; the SEE exists outside the OECD club as the send largest economy in GDP growth. Despite these differences, the SEE shows similar scientific activities in the upstream and industrial activities in the downstream. The SEE emulates part of the LEE's characteristics - in science policies and practice (Pavitt, 2001). Here, emulation refers to a lenient sense. A strict of emulation of institutions will necessarily fail (Boyer, 1996). In the development of science, China stands among top two economies in producing, transformation and exploiting knowledge (Nature, 2017). China also 
mirrors the US in the Co2 emission-China and the US contribute a major part of the world pollution (Lancet, 2017). Since the Chinese science inversely correlated with sustainability (Lancet, 2014), it produces a science-sustainability paradox that merits a systematic analysis to draw a comparison between the two systems.

For instance, China outperforms the US on some development indicators. One such performance captures the rate of national scientific publications in China. In citable scientific and engineering publications, China improves its productivity by 16\% from 1993 to 2015. The USA improves its scientific productivity by $3 \%$ in the same period. The Chinese national patented technology increases by about 23\% from 1994 to 2014; the US national patented technology increases about $3 \%$ in the same period. The Chinese high technology exports have increased by 22.4\% from 1994 to 2015; the US high technology exports have decreased by $40 \%$ (negative) in the same period. Moreover, the major noticeable difference between the types of capitalism for the current argument of science-sustainability paradox in the energy/environment ratios. The energy science production in China overtakes that of the US in 2009. Appendix D shows an increasing trend in the Chinese energy science in publication. However, the environmental science production in China lags the US until recently. In 2016, the Chinese environment science overtakes the US environment science production. Appendix E shows these patterns.

The national science in articles flows more from universities than from industry to the transformation channel, and the codified national science shows credible support to analyse the organisational or national performance in the knowledge creation and transformation for exploitation (Fagerberg, 2005; Smith, 2005). Moreover, the national science falls into the discovery of new knowledge and development of existing knowledge. The discovery represents radical innovation, and the exploitation represents incremental innovation. In the Sino-US comparative spectrum, the LEE in the US carries radical innovation attributes; the SEE in China carries incremental innovation attributes. Naturally, the LEE capitalism in the US shows capabilities in the transformation of radical knowledge, and the SEE capitalism in China shows capabilities in the transformation of incremental knowledge. Authors in the capitalism literature suggest the Chinese institutional comparative disadvantage in the radical science advantage in the incremental science (Hall \& Soskice, 2001). Accordingly, we draw the following.

Hypothesis 5: Chinese environmental science mediation will have a comparative disadvantage to the US in the Co2 emission

Insert Figure 2 about here

\section{Method}

\section{Sample}

Chinese economies plus 29 OECD (organisation of economic cooperation and development) economies make the sample to 30 economies. The summary in Table 1 below shows these economies. The data on these economies represents national science integrated into two main groups: energy discipline and environmental discipline. These disciplines produce citable and non-citable documents. We include citable publications in these countries that span from 1996 to 2016 in a yearly time series pattern. The panel data combines the count of national publications and time span, and this combination supports the empirical reliability of the data and validity of the argument compared to other modes of data analysis. For instance, compared to a cross-section analysis, the panel data fit better to answer correlational and causal questions. This integrated data 
into two main disciplines for 30 national economies depend on minor categories and their underlying mechanisms.

Among the minor categories of the two disciplines, the energy science builds on five sub-disciplines and the environmental science builds on twelve sub-disciplines. Further description, analysis, and discussion on this subdiscipline appear in the later parts of this article in the method section and complementary tables in appendices. The published data came from the common source: the SJR (Scimago Journal \& Country Ranking) 1. The SJR maintains data on every discipline and country from 1996 to 2016. The data on OECD and China on the two disciplines show complete and systematic format. Moreover, we used the World Bank data for the added variables for supplementary analysis, such as economic growth, high technology export and Co2 emissions.

As noted earlier, the published science suits in comparative capitalism argument for several reasons. First, the scientific publications across nations show comparable quantity and quality. The science crosses boundaries through interaction between research organisations, scientists, and the information and communication technologies provide enabling support. Second, scientific publications offer reliable indicators to support the analysis of a national innovation system (Pavitt, 2005; Smith, 1992, 2005). Third, most publications link related sciences directly and indirectly to sustainability. Fourth, the integrated weight of the published science at the macro level supports the time series analysis. We sampled the time series data into a panel for 21 years (1996 to 2016). Fifth, China the second largest economy outside the OECD club. In other international institutions, China joined the World Trade Organisation (WTO) in 1995 and entered the scientific nations. By entering the list of scientific nations, the Chinese published science becomes a comparable indicator across countries.

Sixth, Chinese fourth development plan (973) began in 1993 to support multi-disciplinary basic research in "cutting-edge" technology and promotes promising scientists. Seventh, the Chinese Academy of Sciences (CAS), which encompasses 125 institutions, underwent a major restructuring in the early 1990s to support national science. Seventh, China setup 54 STIPS (Science Industrial parks) in the 1990s. The inclusion of China in the inter-disciplinary and inter-institutional analysis on the one hand and the emergence of reliable data on the other starts in the mid-1990s. Seventh, the evidence shows that the Chinese science raises in quality in the last few years (Freeman \& Huang, 2015). These supporting conditions rationalise the content, context, and process of the analysis on the energy science and environmental science about the $\mathrm{Co} 2$ emission reduction.

The data on the $\mathrm{Co} 2$ emission consists of five measures used in the World Bank estimation for nations around the world. We obtained the data on the 30 countries from the World Bank (WB, 2016). Firstly, the World Bank offers standardised indicators for the national Co2 emission. Appendix $\mathrm{C}$ shows the composition of the $\mathrm{Co} 2$ emission at the national level, integrated from five sources, compared across economies.

\section{Variables}

Dependent variable: We developed the dependent variable from five components adopted in contents and context from the World Bank. Appendix E explains the sources of estimates and construction of the composite variable on $\mathrm{Co} 2$ emission. We transformed the data by taking its log to obtain its normal distribution for robust analysis. The transformed variable became a continuous dependent variable-representing $\mathrm{Co} 2$ emission as the degradation of environmental sustainability.

Independent variables: The independent variables fall into two groups: a disciplinary group that represents national science and the institutional group that represents national economies (capitalisms). In the first group, energy science and environmental science discipline make the independent variables. In the second group, 30 national economies as dummy make the

\footnotetext{
${ }^{1}$ http://www.scimagojr.com/
} 
independent variables. The following two parts show the components of energy science and environmental science. The interaction variables draw on these two groups.

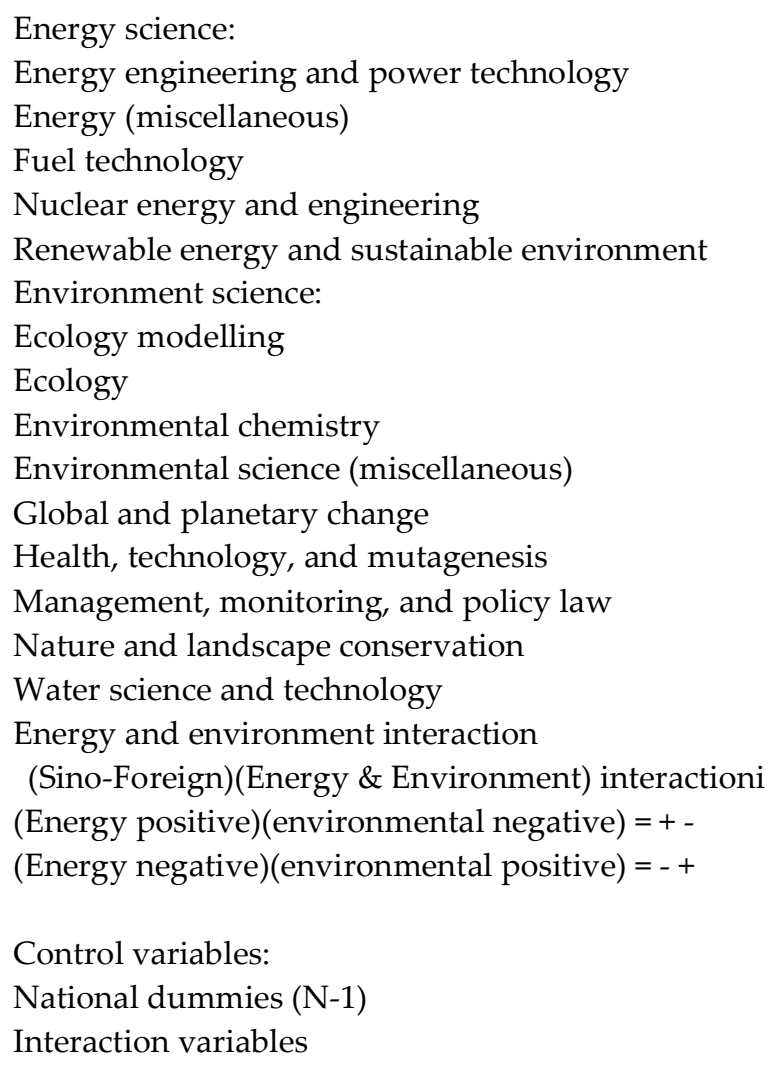

Mediators: A mediator needs to meet several theoretical conditions to be distinguishable from the moderator. The mediator or moderator increases the main coefficient, decreases it, or changes the coefficient direction - positive to negative or vice versa. However, the mediator explains the dependent variable where the moderator does not explain. This assumption raises four theoretical conditions for the mediator.

○ Independent variable variation accounts for the dependent variable

- Independent variable variation accounts for the mediator

○ Mediator variable variation accounts for the dependent variable

- The entry of the mediator in the model should change the effects of the main independent variable.

- The mediating role of the third variable needs to meet these conditions; or else, the independent variable refers to a confounding variable.

Three steps reached the results. First, we tested positive effects of energy and environment on Co2 emissions at the intra-disciplinary level. Second, we integrated positive and negative in two categories: positive and negative correlation groups of energy science; positive and negative correlation groups of environmental science. Third, we focused on the opposite signs of energy and environment in two hypotheses. 


\section{Model E Analysis}

The panel data comprising 23 years and 30 countries in our analysis demands a specific analysis because it shows advantages over conventional measures of cross-section studies (Hsiao, 2003). In using the panel analysis, we used Random Effects based on the Hausman test. The Hausman test suggests whether the null hypothesis shows a statistical difference. If so, the Fixed Effect suits the analysis. Otherwise, the Random Effect model suits the analysis.

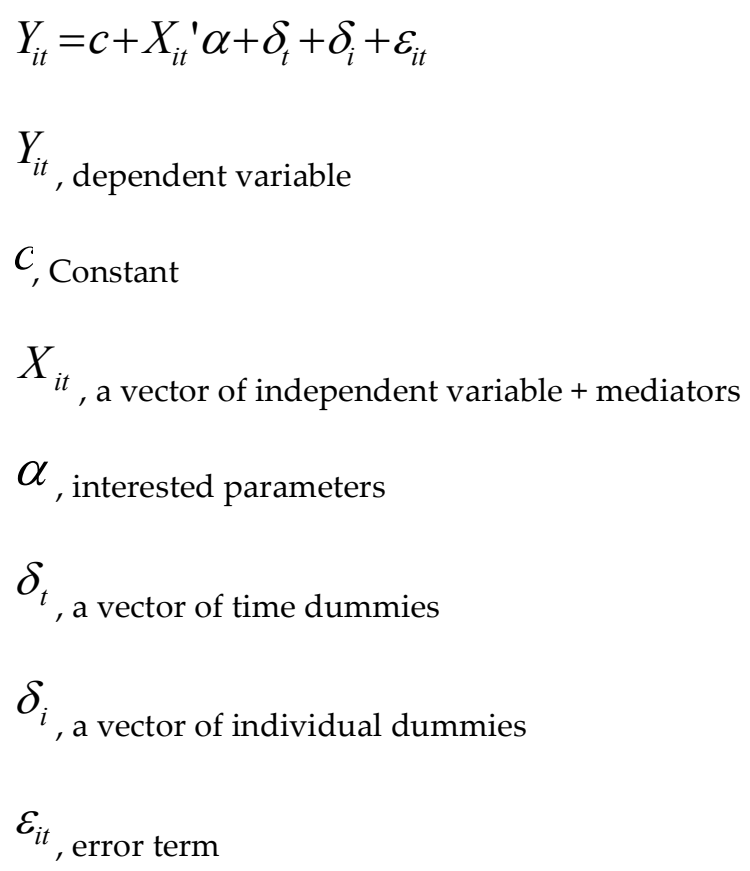

\section{Results}

Table 1 shows a summary statistic of countries. The ratio of the means of energy and environmental sciences publication appears in the last column. The ratio $>1$ means that the national energy science amounts to a higher level of productivity than environmental science. On average, the Chinese energy/environment science exceeds 1 . Closer to China come Japan and South Korea ratios. Their the energy/environment ratios exist near to China.

Insert Table 1 about here

Table 2 shows the interdisciplinary comparison and inter-institutional comparison. Model 1 shows that the comparison between energy science and environmental science reflecting on the Co2 emission in 30 countries. Model 1 does not include the country dummy. Model 2 includes national economies but excludes the science. The US makes the comparative or default category. The Chinese energy science and environment science positively correlate with the $\mathrm{Co} 2$ when compared with the US. 
Insert Table 2 about here

Table 3 shows four models to support the first three hypotheses. Model 1 shows a positive correlation between the energy science and $\mathrm{Co} 2$ emission. We excluded the national dummies. Model 2 shows the national dummies. Model 3 shows a negative correlation between environmental science with the $\mathrm{Co} 2$ emission. Model 4 shows a positive correlation between energy science and environmental science as the outcome, supporting the mediation condition in the next table.

Insert Table 3 about here

Table 4 shows multiple models and their results. In the order of these tests, we note the following ultimate findings to support hypotheses, conclude and discuss in the contexts.

The energy science positively correlates with the Co2 emission.

The environmental science negatively correlates with the Co2 emission.

The energy science positively correlates with the environmental science

The environmental science negatively mediates the effects of energy science on the Co2 emission.

The Chinese energy science positively correlates with the Co2 emission compared to the US energy science.

The Chinese environmental science positively correlates with the Co2 emission compared to the US environmental science.

The Chinese environmental science negatively mediatesii the effects of energy science to Co2 emission compared to the US mediation effects.

Insert Table 4 about here

\section{Discussion}

This study explored the science-sustainability paradox at two levels. The first level addresses the paradox at the interdisciplinary stage to compare the effects of national energy science, environmental science, or the interaction of the two disciplines on the sustainability through the $\mathrm{Co} 2$ emission reduction. The second level addresses the paradox at the inter-institutional stage to compare the disadvantage of Chinese to the US in the distributive role of either discipline or the mediational role of one discipline in the other. The answers to these stages in the analysis led to the 
ultimate purpose of the study on the Chinese science-sustainability paradox. These stages in the analysis follow three precise empirical questions to conclude the theoretical discussion.

o Does Chinese energy science increase Co2 emission compared to the US?

o Does Chinese environment science increase Co2 emission compared to the US?

o Does environmental science positively mediate the effect of energy science on the Co emission compared to the US?

Before turn to these answers to these precise questions of the inter-institutional comparison and science-sustainability paradox of China, we draw brief answers from the generic analysis. The finding shows that energy science increases the $\mathrm{Co} 2$ emission, and the environmental science decreases the $\mathrm{Co} 2$ emission among 30 countries in the sample. Moreover, the environmental science mediates the effects of energy science. Therefore, the interaction between the environmental science and energy science changes the positive effect of energy science into negative effects on the $\mathrm{Co} 2$ emission. This general finding supports the mediation path after controlling for national dummies.

Regarding the three questions in the Sino-US comparative setting, the answer to the first question affirms that energy science increases the $\mathrm{Co} 2$ emission compared to the US. The positive correlation between energy science and the $\mathrm{Co} 2$ emission offers a paradoxical context for two reasons. Firstly, Chinese national energy science productivity surpasses the US productivity. For instance, since 2007, the size of the publications in energy science outpaces the size of the energy science publications in the US. Appendix D shows the Chinese lead in energy science compared to the US on the timeline. Second, energy science offers in China incremental developments for economic efficiencies (Gan, 1998; Zhang et al., 2017b). These efficiencies are driven arguments to leave the exogenous structures such as social actors, community and institutions out of the analysis (Liu et al., 2017; Merrill \& Sintov, 2016; Zhang et al., 2017a). Instead, the environmental science in the second question addresses this intermediary issue.

The evidence to the second question shows that Chinese environmental science decreases the $\mathrm{Co} 2$ emission compared to the US. There are three sources of surprise in this answer. First, the environmental science productive falls below the energy science productivity in China. Second, the environmental science productivity in China stays below the level in the US until 2016, and in it catches up with the US in 2017. Appendix E shows the Sino-US role. Third, the research on Co2 emission reduction in China reflects improvements in and development of existing sources-coal, oil and nuclear (Gan, 1998; Merrill \& Sintov, 2016; Schweizer-Ries, 2008; Zhang et al., 2017b). These conventional technological paths offer incremental solutions. The environmental sustainability needs radical solutions, both technical and social. In other words, the necessary preventive and curative policies depend on the institutional settings.

In response to the third question, the environmental science in China negatively mediates the positive effect of the energy. This result hits the outstanding issue of inter-disciplinary and inter-institutional comparison. While the research on China alone informs the research policy and practice, it leaves questions of capitalism, policies, incentives, and structural changes that support the environmental science from multidisciplinary perspectives. The three answers to preceding questions in conjunction with Table 3 offer three respective insights.

First, the knowledge of energy science in China exceeds the US knowledge on energy science regarding publications; the $\mathrm{Co} 2$ continues to exceed in China compared to the US. The opposite logic gives the first insight of paradox. Second, the environmental science in the US exceeds that in China; the $\mathrm{Co} 2$ in the US continue to increase in the US compared to that in China. The lagging of environmental science in China and the leading position in the Co2 reduction offers the secondly related paradox. Third, the mediation effect shows that the environmental path to the economic growth as well as sustainability may outperform that in the US if Chinese increases its attention towards environmental science as much as it does to energy science. The contextual interpretation of these findings shows implications in policy and practice.

In the context of the extant literature, our research focus and findings differ in three ways. First, most of the prior research focuses on the broader context such as regulatory policies, tax 
incentives, and public-private partnerships in the $\mathrm{Co} 2$ emission. We focused on the content of science and its transformation into $\mathrm{Co} 2$ emission reduction at the concrete level. In this sense, the prior literature offers a much broader explanation than the processes related to the science-sustainability phenomenon. Second, the prior research focuses on narrow economic activities in a specific sector. For instance, some prior ideas allude to the conservation as well as energy demand expansion (Gan, 1998). The Jevons Paradox points to the conflicting logic of incremental efficiencies and depleting energy resources (Jevons, 1866). This narrow focus on one sector suggests industrial processed and development but lacks discoveries of new products, processes, and industries. Third, some researchers use the environmental importance as predictors and cost/benefits as mediators to find the weak role of cost/benefits as mediators in China (Liu et al., 2017). We argue that the environmental science reflects multidisciplinary knowledge, actors, agencies, and social logics (Rau, Goggins, \& Fahy, 2018). The environmental science forms a broader context for meaning and action of multiple dimensions for sustainability. Therefore, the environmental science analogously alludes to the structural mechanism in the transformation of knowledge content and economic values.

Although some writers have addressed the demand side of the equation in the science-sustainability relationship, they have left the integrated path of environmental science for sustainability unexplained. In our study, the demand perspective integrates the organisational issues with the environmental issues. Focusing on the consumer, it develops a perspective on sustainability in two ways. First, the customer-driven public awareness enhances green purchasing behaviour. Second, the structural change induces sustainability. Although the green customer and structural incentives for the environmental sustainability explain the policy effect from the demand side, they primarily focus on the downstream perspective. The focus in the downstream of the value chain implies that the products and technologies incrementally progress. Such incremental improvement, however, meets the Jevons Paradox that we noted earlier. In our focus, the issue of knowledge input such as energy science and knowledge context as the mediating context aligns with the integrative policies and practice.

The interdisciplinary relationship between energy and science suggests that the input related science-such as energy research and innovation-has two focuses. One perspective relates to economic issues. The energy science serves the efficiency and business purpose in this focus. For instance, energy science consists of fossil fuel exploration, drilling, refining and other related engineering activities. Similarly, science based on the engineering of automobiles, aviation and machinery attract the incremental science rather than radical science in the sustainability paradigm. As a part of the energy science, these technological developments contribute to economic efficiencies. In comparison to this inside perspective, outside perspective on the environmental science encompasses multiple mechanisms at the scientific level, and social level supports the transformation of national science. At the scientific level, discoveries in the environment contribute to radical innovation, new products and process, and new markets (Antonelli \& Fassio, 2016; Boyer, 2011; Garud, Jain, \& Kumaraswamy, 2002; Garud \& Karnøe, 2003). This macro-level focus on the national science implications for the inter-institutional comparison.

The inter-institutional comparison answers the question about the fit between national institutions and respective science in which the latter shapes the former and vice versa (Boyer, 2011). For instance, the earlier noted LEE (liberal entrepreneurial economy) of the USA and the SEE (state entrepreneurial economy) link actors and structures on behavioural paths in peculiar and partially overlaps. The LEE capitalism shows its efficient and effective role in the radical innovation because it outweighs the exploration and transformation of environmental sciences (Hall \& Soskice, 2001). Theoretically, it seems plausible that the LEE in the US revels in hegemony in the radical innovation productivity. In contrast, the SEE in China stays in the range of incremental innovation attributes. It improves operational efficiencies of the existing knowledge about energy input and output. However, the SEE capitalism stays below the performance of the LEE capitalism for the last decade. The comparison between the LEE and SEE capitalism need attention for the proposition of 
science-sustainability paradox. For the policy purpose, we recommend that the SEE of China attend to environmental science to support its advantages in the energy science. Some national level structural development and incentive strategies for the matching practice offers potential advantages.

The study leaves some limitations as a room for future research. First, it covers the supply side of the science rather than demand side of it - the consumer's interaction and feedback. The transformation of knowledge through interaction with users leads to important developments and implications in the sustainability situation. Second, the tenet of effective capitalism demands that internal processes bridge the gap between the two poles - the input and the output. For instance, university-industry relation, the inter-firm alliance, and the government role in the tripartite industrial system need attention. Third, the OECD economies limit the analysis to lead nations. Within these economies, some variables have some missing data. Fourth, the codified science in publications varies in quality. The quality of codified disciplines merits attention in the future research. Fifth, the transformation of national science answer one question, but not the other. Does, LEE or SEE outperform in the transformation of non-national science (discoveries elsewhere) into sustainable economic development - a reduction of the Co2 emission?

Funding: This research was funded by [National Social Science Foundation of China] grant number [13CGL045]

Conflicts of Interest: The authors declare no conflict of interest.

\section{REFERENCES}

Anand, S., \& Sen, A. K. 2000. Human Development and Economic Sustainability. World Development, 28(12): 2029-2049.

Antonelli, C., \& Fassio, C. 2016. Academic knowledge and economic growth: are scientific fields all alike? Socio-Economic Review, 14(3): 537-565.

Aoki, M. 2013. Historical sources of institutional trajectories in economic development: China, Japan and Korea compared. Socio-Economic Review, 11: 233-263.

Block, F., \& Keller, M. R. 2009. Where Do Innovations Come From? Changes in the U.S. Economy, 1970-2006. Socio-Economic Review, 7: 459-483.

Block, F., \& Somers, M. R. 2014. The Power of Market Fundamentalism: Karl Polanyi's Critique Boston, MA: Harvard University Press.

Boyer, R. 1996. The Convergence Hypothesis Revisited: Globalization but Still the Century of Nations? . In S. Berger, \& R. Dore (Eds.), National Diversity and Global Capitalism: 29-59. Ithaca Cornell University Press.

Boyer, R. 2004. New growth regimes, but still institutional diversity. Socio-Economic Review 2(1): 1-32.

Boyer, R. 2005. How and why capitalisms differ. Economy and Society, 34(4): 509-557.

Boyer, R. 2008. Pierre Bourdieu, a Theoretician of Change? The View from Regulation Theory. In A. Ebner, \& N. Beck (Eds.), The Institutions of the Market: Organizations, Social Systems and Governance: 348-397. Oxford Oxford University Press.

Boyer, R. 2011. Are there laws of motion of capitalism? Socio-Economic Review, 9: 59-81

Campbell, J. L. 2001. Institutional Analysis and the Role of Ideas in Political Economy. In J.

L. Campbell, \& O. K. Pedersen (Eds.), The rise of neoliberalism and institutional analysis: 159-189. Princeton, N.J.: Princeton University Press. 
Campbell, J. L. 2011. The US financial crisis: lessons for theories of institutional complementarity. Socio-Economic Review, 9(2): 211-234.

Chen, L., Thapa, B., \& Yan, W. 2018. The Relationship between Tourism, Carbon Dioxide Emissions, and Economic Growth in the Yangtze River Delta, China. Sustainability, 10(7), 1-20.

Deaton, A. 2013. The Great Escape: Health, Wealth, and the Origins of Inequality. Princeton, NJ: Princeton University Press.

Di Domenico, M., Haugh, H., \& Tracey, P. 2010. Social Bricolage: Theorizing Social Value Creation in Social Enterprises. Entrepreneurship Theory \& Practice, 34(4): 681-703.

Douglas, M. 1986. How Institutions Think. Syracuse: Syracuse University Press.

Duckett, J. 1996. The emergence of the entrepreneurial state in contemporary China. Journal of The Pacific Review 9(2): 180-198.

Duymedjian, R., \& Ruling, C. C. 2010. Towards a foundation of bricolage in organization and management theory. Organization Studies, 31: 133-151.

Eisinger, K. P. 1988. The Rise of The Entrepreneurial State: State and Local Development Policy in the United States. Madison: The University of Wisconsin Press.

Etzkowitz, H. 2003. Research groups as 'quasi-firms': the invention of the entrepreneurial university. Research Policy, 32(1): 109-121.

Fagerberg, J. 2005. Innovation: A Guide to the Literature. In J. Fagerberg, D. C. Mowery, \& R. Nelson (Eds.), The Oxford Handbook of Innovation: 1-26. New York: Oxford University Press.

Freeman, C. 2002. The Learning Economy and International Inequality. In D. Archibugi, \& B.-A. Lundvall (Eds.), The Globalizing Learning Economy: 147-162. Oxford: Oxford University of London.

Freeman, R. B., \& Huang, W. 2015. Collaborating with People Like Me: Ethnic Coauthorship within the United States. Journal of Labor Economics, 33(S1): S289-S318.

Friedman, M. 1962. Capitalism and Freedom. Chicago, IL: University of Chicago Press.

Gan, L. 1998. Energy development and environmental constraints in China Energy Policy, 26(2): 119-128.

Garud, R., Jain, S., \& Kumaraswamy, A. 2002. Institutional entrepreneurship in the sponsorship of common technological standards: The case of Sun Microsystems and Java. Academy of Management Journal, 45: 196-214.

Garud, R., \& Karnøe, P. 2003. Bricolage versus breakthrough: distributed and embedded agency in technology entrepreneurship. Research Policy, 32: 277-230.

Giddens, A. 1991. Modernity and Self-Identity. Stanford, CA: Standford University Press.

Hall, P. A., \& Soskice, D. (Eds.). 2001. Varieties of Capitalism: The Institutional Foundation of Comparative Advantage. London: Oxford University Press.

Hollingsworth, J. R. 2003. Advancing the Socio-economic Paradigm with Institutional Analysis Socio-Economic Review, 1(1): 130-134.

Hsiao, C. 2003. Analysis of Panel Data. Cambridge: Cambridge University Press.

Jevons, W. S. 1866. The coal question : An enquiry concerning the progress of the national and the probable exhaustion of our coal-mines. London: Macmillan and Company.

Kenworthy, L. 2006. Institutional Coherence and Macroeconomic Performance. Socio-Economic Review 4: 69-91. 
Lancet. 2014. China's food safety: a continuing global problem. Lancet, 384(9941): 377.

Lancet. 2017. Estimates and 25-year trends of the global burden of disease attributable to ambient air pollution: an analysis of data from the Global Burden of Disease Study 2015. The Lancet, 389: 1907-1918.

Levi-Strauss, C. 1966. The Savage Mind. Chicago: University of Chicago Press.

Liu, F., Lyu, T., Pan, L., \& Wang, F. 2017. Influencing factors of public support for modern coal-fired power plant projects: An empirical study from China Energy Policy, 105: 398-406.

Lundvall, B.-Å., Johnson, B., Andersen, E. S., \& Dalum, B. 2002. National systems of production, innovation and competence building. Research Policy, 31(2): 213231.

March, J. G. 1999. The Pursuit of Organizational Intelligence. Oxford, Malden: Blackwell Business.

March, J. G. 2014. Susan Sontag and Heteroscedasticity. In R. Swedberg (Ed.), Theorizing in Social Sciences: The Context of Discovery 195-204. Stanford, CA: Stanford University Press.

Mazzucato, M. 2014. The Entrepreneurial State: Debuking Public vs. Private Sector Myths. London: Anthem Press.

Meadows, D., Meadows, D., Randers, J. R., \& Behrens III, W. W. 1972. Limits to Growth: a report for the Club of Rome's project on the predicament of mankind, Part 1: Universe Books.

Merrill, R., \& Sintov, N. 2016. An Affinity-to-Commons Model of Public Support For Environmental Energy Policy. Energy Policy, 99: 88-99.

Nature. 2017. Global Scientific Research Performance. Nature Index, http://www.natureindex.com/country-outputs/generate/All/global/All/weighted score (Accessed 30/3/2017).

North, D. 1981. Structure and change in economic history. New York: Norton.

North, D. 1990. Institutions, Institutional Change and Economic Performance. Cambridge: Cambridge University Press.

Pavitt, K. 2001. Public Policies to Support Basic Research: What Can the Rest of the World Learn from US Theory and Practice? (And What They Should Not Learn). Research Policy, 10(3): 761-779.

Pavitt, K. 2005. Innovation Processes. In J. Fagerberg, D. C. Mowery, \& R. Nelson (Eds.), The Oxford Handbook of Innovation: 86-114. New York: Oxford University Press.

Polanyi, K. 1944. The great transformation. New York: Rinehart.

Polanyi, M. 1967. The tacit dimension. London: Routledge \& Kegan Paul.

Qiu, H. H., \& Yang, J. 2018. An Assessment of Technological Innovation Capabilities of Carbon Capture and Storage Technology Based on Patent Analysis: A Comparative Study between China and the United States. Sustainability, 10(3), 877.

Rau, H., Goggins, G., \& Fahy, F. 2018. From invisibility to impact: Recognising the scientific and societal relevance of interdisciplinary sustainability research Research Policy, 47: 266-276.

Schotter, A. 1981. The economic theory of social institutions. Cambridge: Cambridge University Press.

Schweizer-Ries, P. 2008. Energy sustainable communities: Environmental psychological investigations. Energy Policy, 36(11): 4126-4135. 
Sen, A. K. 1985. Commodities and Capabilities. Oxford: Oxford University Press.

Sen, A. K., Stiglitz, J. E., \& Fitoussi, J.-P. 2010. Mismeasuring our lives: why GDP doesn't add up: the report. . New York New Press.

Smith, K. 1992. Technological Innovation Indicators : Experience and Prospects. Science and Public Policy, 19(6): 24-34.

Smith, K. 2005. Measuring Innovation. In J. Fagerberg, D. C. Mowery, \& R. Nelson (Eds.), The Oxford Handbook of Innovation: 148-177. New York: Oxford University Press.

Sorrell, S. 2009. Jevons' Paradox revisited: The evidence for backfire from improved energy efficiency. Energy Policy, 37(4): 1456-1469.

Stinchfield, B. T., Nelson, R. E., \& Wood, M. S. 2013. Leanring from Levi-Strauss' Legacy: Art, Craft, Engineering, Bricolage, and Brokerage in Entrepreneurship. Entrepreneurship Theory \& Practice, 37(4): 889-921.

Storz, C., Amable, B., Casper, S., \& Lechevalier, S. 2013. Bringing Asia into the comparative capitalism perspective. Socio-Economic Review, 11(2): 217-232.

Swedberg, R. (Ed.). 2014. Theorizing in Social Science: The Context of Discovery. Stanford, CA: Stanford University Press.

Tiberghien, Y. 2007. Entrepreneurial State: Reforming Corporate Governance in France, Japan and Korea. Ithaca, New York: Cornell University Press.

Vallas, S. P., \& Kleinman, D. L. 2008. Contradiction, convergence and the knowledge economy: the confluence of academic and commercial biotechnology. Socio-Economic Review, 6(2): 283-311.

Von Hippel, E. 1988. The sources of innovation. New York: Oxford University Press.

WB. 2016. Countries and Economies. The World Bank: IBRD-IDA, http://data.worldbank.org/country (Accessed in July 2016).

Yan, Z., Yi, L., Du, K., \& Yang, Z. 2017. Impacts of Low-Carbon Innovation and Its Heterogeneous Components on CO2 Emissions. Sustainability, 9(4), 548.

Zhang, X., Winchester, N., \& Zhang, X. 2017a. The future of coal in China. Energy Policy, 110: 644-652.

Zhang, Y.-J., Peng, Y.-L., Chao-Qun, M., \& Shen, B. 2017b. Can environmental innovation facilitate carbon emissions reduction? Evidence from China Energy Policy, 100: 18-28. 
Table 1: Summary statistics

\begin{tabular}{|c|c|c|c|c|c|c|c|c|c|}
\hline \multirow{2}{*}{$\begin{array}{l}\text { Countries } \\
\text { Variable }\end{array}$} & \multicolumn{4}{|c|}{ Energy (E1) } & \multicolumn{4}{|c|}{ Environment (E2) } & \multirow{2}{*}{$\begin{array}{l}\text { Mean } \\
\text { Ratio } \\
\text { E1/E2 }\end{array}$} \\
\hline & Mean & $\begin{array}{l}\text { Std. } \\
\text { Dev. }\end{array}$ & Min & Max & Mean & $\begin{array}{l}\text { Std. } \\
\text { Dev. }\end{array}$ & Min & Max & \\
\hline The USA & 327.5 & 1920.0 & 0 & 17356 & 707.9 & 3924.7 & 0 & 29189 & $46 \%$ \\
\hline China & 336.5 & 2341.2 & 0 & 25721 & 311.2 & 2297.0 & 0 & 26558 & $108 \%$ \\
\hline $\mathrm{AU}$ & 30.6 & 207.4 & 0 & 2433 & 108.0 & 640.6 & 0 & 6200 & $28 \%$ \\
\hline AT & 9.5 & 56.4 & 0 & 573 & 23.9 & 141.0 & 0 & 1257 & $39 \%$ \\
\hline $\mathrm{BE}$ & 12.6 & 79.6 & 0 & 822 & 31.7 & 184.9 & 0 & 1687 & $40 \%$ \\
\hline CA & 53.2 & 321.7 & 0 & 3046 & 135.4 & 768.0 & 0 & 6119 & $39 \%$ \\
\hline $\mathrm{CL}$ & 2.5 & 16.0 & 0 & 219 & 10.5 & 64.4 & 0 & 630 & $24 \%$ \\
\hline $\mathrm{CZ}$ & 8.4 & 58.3 & 0 & 771 & 19.6 & 125.1 & 0 & 1399 & $43 \%$ \\
\hline DE & 85.6 & 499.1 & 0 & 4676 & 159.8 & 899.8 & 0 & 7290 & $54 \%$ \\
\hline DK & 12.2 & 83.2 & 0 & 1062 & 30.8 & 178.2 & 0 & 1692 & $39 \%$ \\
\hline $\mathrm{FI}$ & 10.5 & 72.4 & 0 & 1092 & 30.7 & 171.6 & 0 & 1445 & $34 \%$ \\
\hline FR & 55.9 & 331.8 & 0 & 3048 & 110.2 & 631.6 & 0 & 5380 & $51 \%$ \\
\hline GR & 10.2 & 62.5 & 0 & 558 & 23.9 & 140.6 & 0 & 1160 & $43 \%$ \\
\hline HU & 3.6 & 21.7 & 0 & 217 & 9.6 & 56.1 & 0 & 515 & $37 \%$ \\
\hline $\mathrm{IE}$ & 4.4 & 28.9 & 0 & 298 & 11.9 & 71.2 & 0 & 612 & $37 \%$ \\
\hline IL & 5.1 & 28.8 & 0 & 222 & 13.9 & 76.7 & 0 & 597 & $37 \%$ \\
\hline IT & 44.5 & 290.8 & 0 & 3796 & 87.1 & 525.3 & 0 & 5053 & $51 \%$ \\
\hline$J P$ & 108.1 & 602.9 & 0 & 4470 & 112.9 & 627.4 & 0 & 4640 & $96 \%$ \\
\hline $\mathrm{KR}$ & 45.9 & 305.3 & 0 & 3541 & 48.7 & 321.2 & 0 & 3355 & $94 \%$ \\
\hline$M X$ & 12.6 & 75.1 & 0 & 738 & 26.7 & 159.5 & 0 & 1397 & $47 \%$ \\
\hline NL & 22.6 & 138.9 & 0 & 1353 & 64.8 & 370.6 & 0 & 3228 & $35 \%$ \\
\hline NO & 16.8 & 105.4 & 0 & 1076 & 31.2 & 181.1 & 0 & 1687 & $54 \%$ \\
\hline $\mathrm{NZ}$ & 3.8 & 22.3 & 0 & 183 & 25.5 & 143.8 & 0 & 1140 & $15 \%$ \\
\hline PO & 14.0 & 87.1 & 0 & 990 & 43.4 & 260.6 & 0 & 2595 & $32 \%$ \\
\hline PT & 10.1 & 71.1 & 0 & 895 & 26.0 & 174.4 & 0 & 1978 & $39 \%$ \\
\hline SE & 36.1 & 239.7 & 0 & 2613 & 94.2 & 572.3 & 0 & 5269 & $38 \%$ \\
\hline SW & 19.5 & 123.5 & 0 & 1336 & 50.1 & 284.9 & 0 & 2529 & $39 \%$ \\
\hline $\mathrm{CH}$ & 16.6 & 101.0 & 0 & 1016 & 42.0 & 249.2 & 0 & 2286 & $40 \%$ \\
\hline TR & 18.0 & 112.0 & 0 & 1018 & 38.6 & 236.1 & 0 & 2116 & $3 \%$ \\
\hline UK & 71.9 & 426.3 & 0 & 4256 & 199.4 & 1110.3 & 0 & 8829 & $23 \%$ \\
\hline
\end{tabular}

E1/E2 Ratio $=($ mean) energy science $\%$ of environment science 
Table 2: Science and economies (institutions)

\begin{tabular}{|c|c|c|c|}
\hline Variables & Model 1 & Model 2 & Model 3 \\
\hline Constant & $15(1.26) * * *$ & $15.74(.85)^{* * *}$ & $19.13(.147)^{* * *}$ \\
\hline US & & $<$ default $>$ & $<$ default $>$ \\
\hline AU & & $1.32(.33)^{* * *}$ & $-1.85(1.1)$ \\
\hline $\mathrm{AT}$ & & $0.03(.33)$ & $-3.44(1.25)^{* *}$ \\
\hline $\mathrm{BE}$ & & $1.06(.33)^{* * *}$ & $-2.57(1.24)^{*}$ \\
\hline CA & & $-0.64(.33)$ & $-3.76(1.04)^{* * *}$ \\
\hline $\mathrm{CL}$ & & $-0.19(.34)$ & $-4.01(1.27)$ \\
\hline $\mathrm{CZ}$ & & $3.93(.33)^{* * *}$ & $0.06(1.26)$ \\
\hline $\mathrm{DE}$ & & $1.11(.33)^{* * *}$ & $-1.86(1.07)$ \\
\hline DK & & $-0.98(.33)^{* * *}$ & $-4.63(1.24)^{* * *}$ \\
\hline FI & & $0.44(.33)$ & $-3.31(1.24)^{* *}$ \\
\hline FR & & $1.82(.33)^{* * *}$ & $-1.39(.1 .13)$ \\
\hline GR & & $-0.64(.33)$ & $-4.23(1.25)^{* * *}$ \\
\hline $\mathrm{HU}$ & & $-0.44(.33)$ & $-4.07(1.28)^{* * *}$ \\
\hline IE & & $0.30(.33)$ & $-3.44(1.28)^{* *}$ \\
\hline IL & & $-2.11(.33)^{* * *}$ & $-5.49(1.27)^{* * *}$ \\
\hline IT & & $-2.29(.33)^{* * *}$ & $-5.40(1.16)^{* * *}$ \\
\hline JP & & $-0.44(.33)$ & $-3.55(1.28)^{* *}$ \\
\hline KR & & $0.80(.33)^{* *}$ & $-2.75(1.29)^{*}$ \\
\hline MX & & $-4.48(.33)^{* * *}$ & $-7.93(1.25)^{* * *}$ \\
\hline NL & & $-2.29(.33)^{* * *}$ & $-5.63(1.17)^{* * *}$ \\
\hline $\mathrm{NO}$ & & $-2.55(.33)^{* * *}$ & $-6.00(1.25)^{* * *}$ \\
\hline $\mathrm{NZ}$ & & $0.66(.33)$ & $-3.02(1.23)^{* *}$ \\
\hline $\mathrm{PO}$ & & $4.93(.33)^{* * *}$ & $1.24(1.21)$ \\
\hline PT & & $-1.50(.33)^{* * *}$ & $-5.02(1.25)^{* * *}$ \\
\hline SE & & $-0.38(.33)$ & $-3.72(1.12)^{* * *}$ \\
\hline SW & & $1.79(.33)^{* * *}$ & $-1.64(1.20)$ \\
\hline $\mathrm{CH}$ & & $1.34(.33)^{* * *}$ & $-2.07(1.22)$ \\
\hline TR & & $2.44(.33)^{* * *}$ & $-1.12(1.230$ \\
\hline UK & & $-0.59(.33)$ & $-3.37(.01)^{* * *}$ \\
\hline $\mathrm{CN}$ & & $6.71(.33)^{* * *}$ & $3.85(1.40)^{* *}$ \\
\hline Energy & $0.68(.22)^{* *}$ & & $0.01(.28)$ \\
\hline Environment & $-0.50(.26) \pm$ & & $-0.09(.29) * * *$ \\
\hline F-statistics & $20 * * *$ & $2696.6^{* * *}$ & $2150 * * *$ \\
\hline R-square & 0.03 & 0.22 & 0.22 \\
\hline DOF & 2 & 29 & 31 \\
\hline $\mathrm{N}$ & 626 & 690 & 600 \\
\hline
\end{tabular}

Dependent variable $=$ composite variable $(5$ variables of Co2 emission); US $=$ default $* * * \mathrm{p}<.001$

$* * \mathrm{p}<.01$

$* \mathrm{p}<.05$

$\pm \mathrm{p}<.10$ 
Table 3: Environmental science mediation (Appendix G)

\begin{tabular}{|c|c|c|c|c|}
\hline Variables & Model 1 & Model 2 & Model 3 & Model 4 \\
\hline Constant & $21.7(2.8)^{* * *}$ & $15.5(.89)^{* * *}$ & $15.5(.90)^{* * *}$ & $15.45(.81)^{* * *}$ \\
\hline 29 National dummies & <included > & <included> & $<$ included $>$ & $<$ included $>$ \\
\hline Energy science & $.45(.36)$ & & & \\
\hline Environment science & $-.30(.41)$ & & & \\
\hline (Energy)(environment) & $-.08(.04)^{* *}$ & & & \\
\hline Sino-US (energy) & & $0.67(.04)^{* * *}$ & $5.98(1.1)^{* * *}$ & $0.63(1.56)$ \\
\hline Sino-US (environment) & & & $-5.42(1.1)^{* * *}$ & $2.04(1.95)$ \\
\hline Sino-US (energy*environment) & & & & $-0.22(.05)^{* * *}$ \\
\hline F-statistics & $2138 * * *$ & $1723 * * *$ & $2071 * * *$ & $2132 * * *$ \\
\hline R-square & 0.27 & 0.18 & 0.19 & 0.19 \\
\hline DOF & 32 & 30 & 30 & 31 \\
\hline $\mathrm{N}$ & 600 & 600 & 600 & 600 \\
\hline
\end{tabular}

Dependent variable $=$ composite variable $(5$ variables of Co 2 emission); US \& CN default $* * * \mathrm{p}<.001$

$* * \mathrm{p}<.01$

$* \mathrm{p}<.05$ 
Figure 1: Conceptualisation of science and its transformation

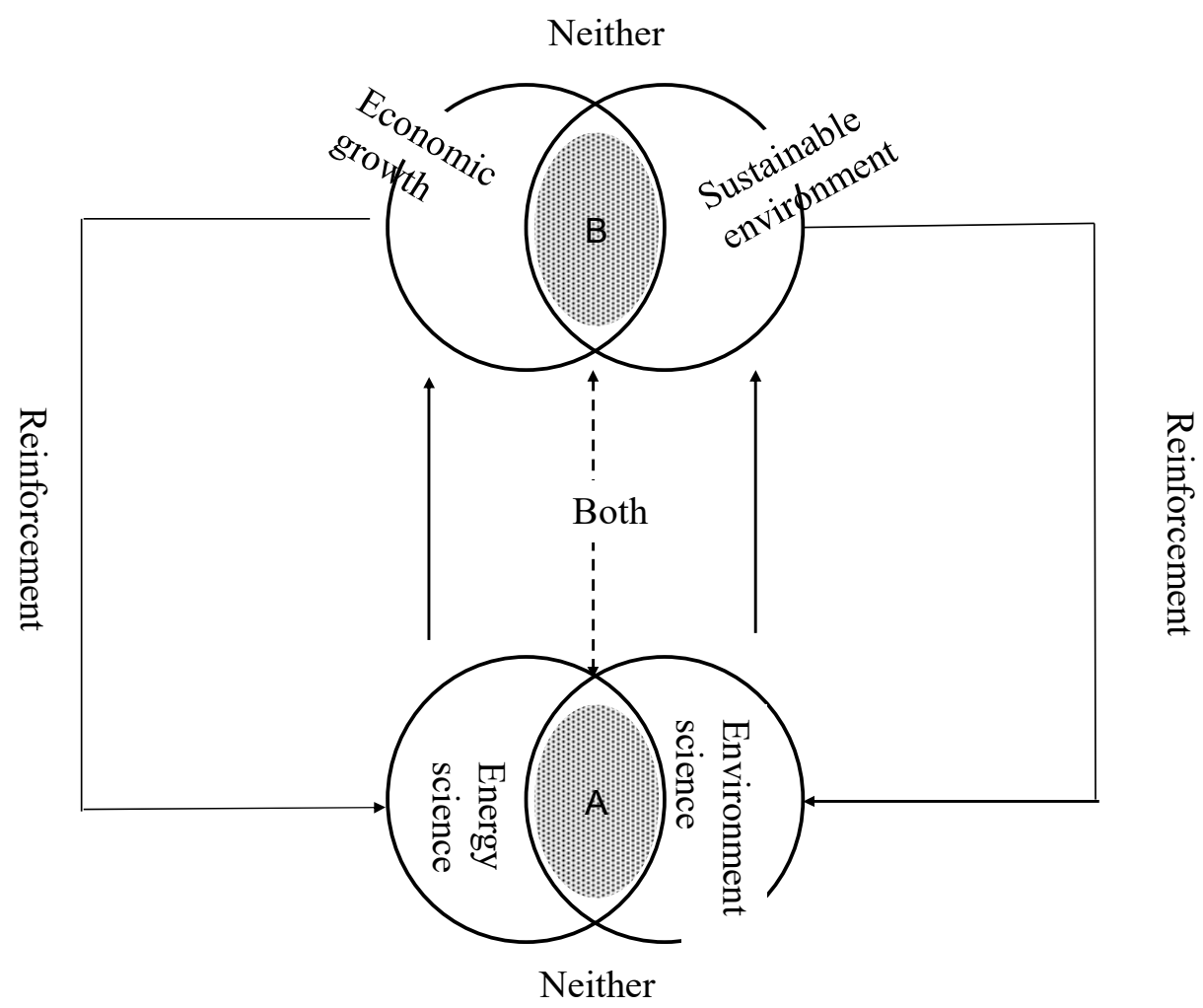


Figure 2: Analytical model

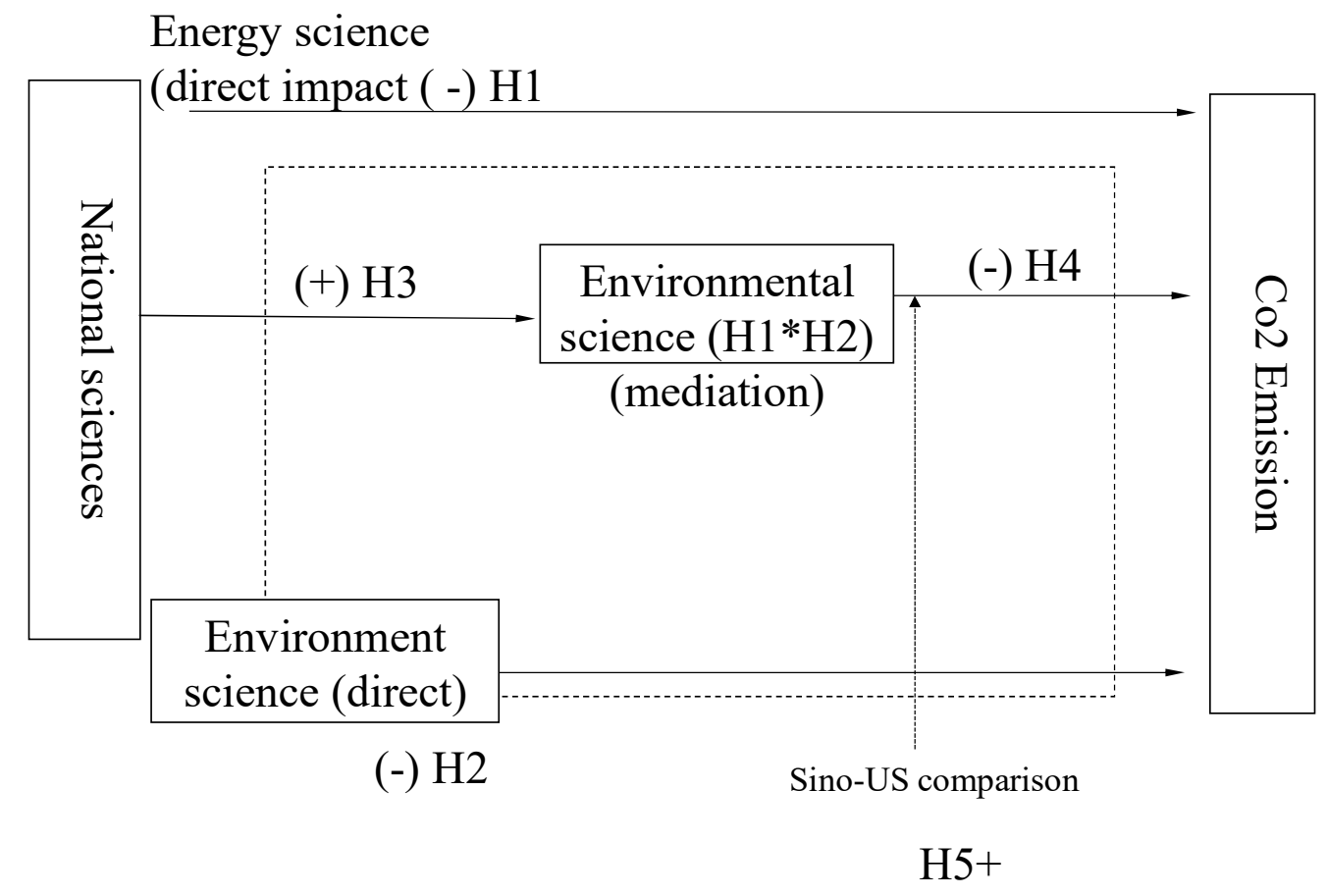


Appendix A: Increase in Co2 emission in the world

Global carbon emissions from fossil fuels and ind ustry

40 trillion $\mathrm{kg}$

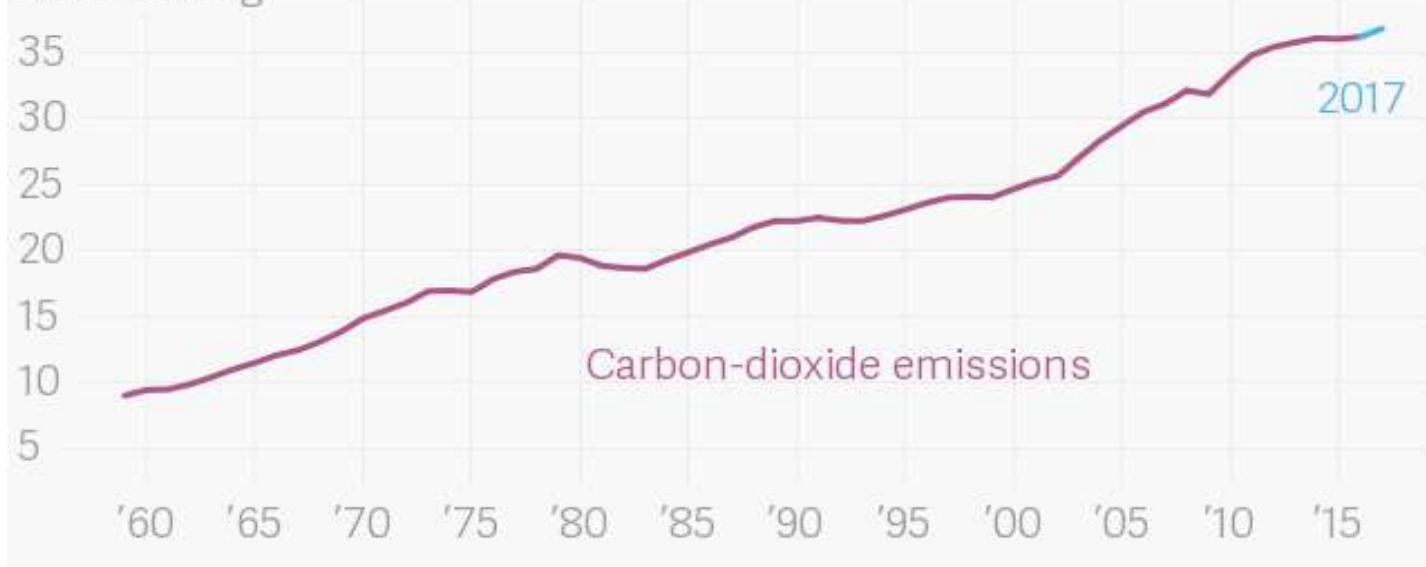

Source: Global Carbon Project (http://www.globalcarbonproject.org) 
Appendix B: Co2 emission in 1996

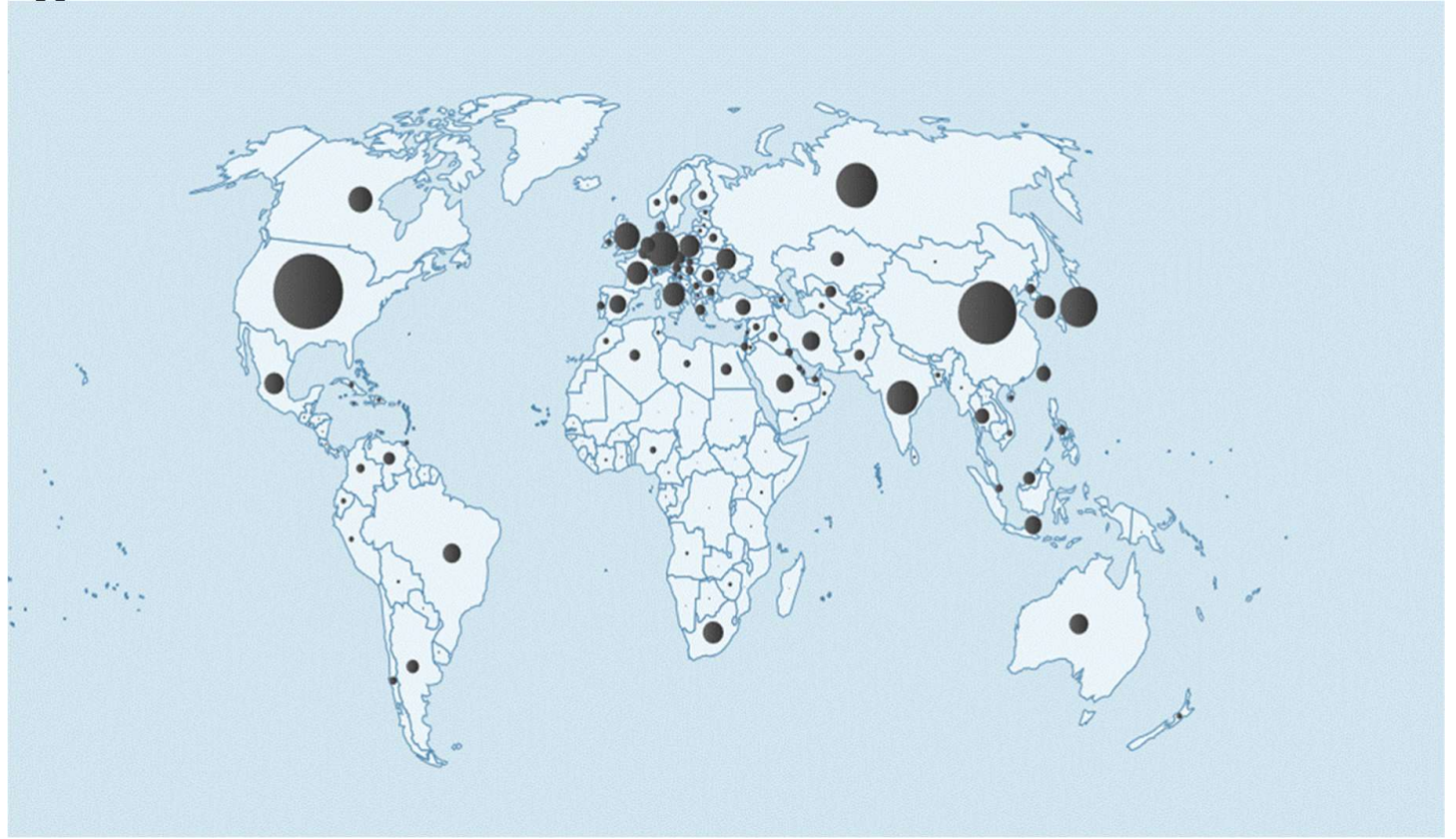

Source: Global Carbon Project (http://www.globalcarbonproject.org) 
Appendix C: Co2 emission in 2016

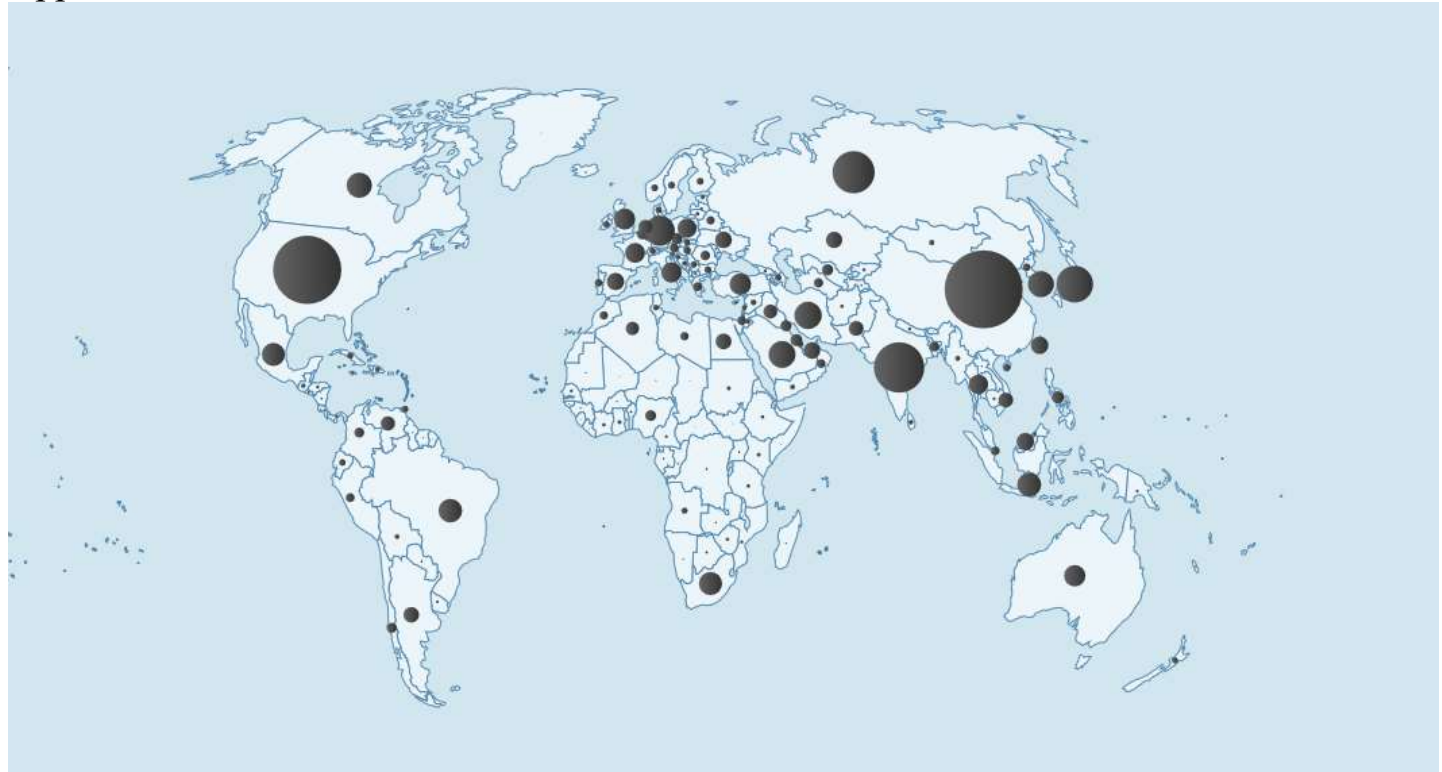

Source: Global Carbon Project (http://www.globalcarbonproject.org) 
Appendix D: China and the US energy science

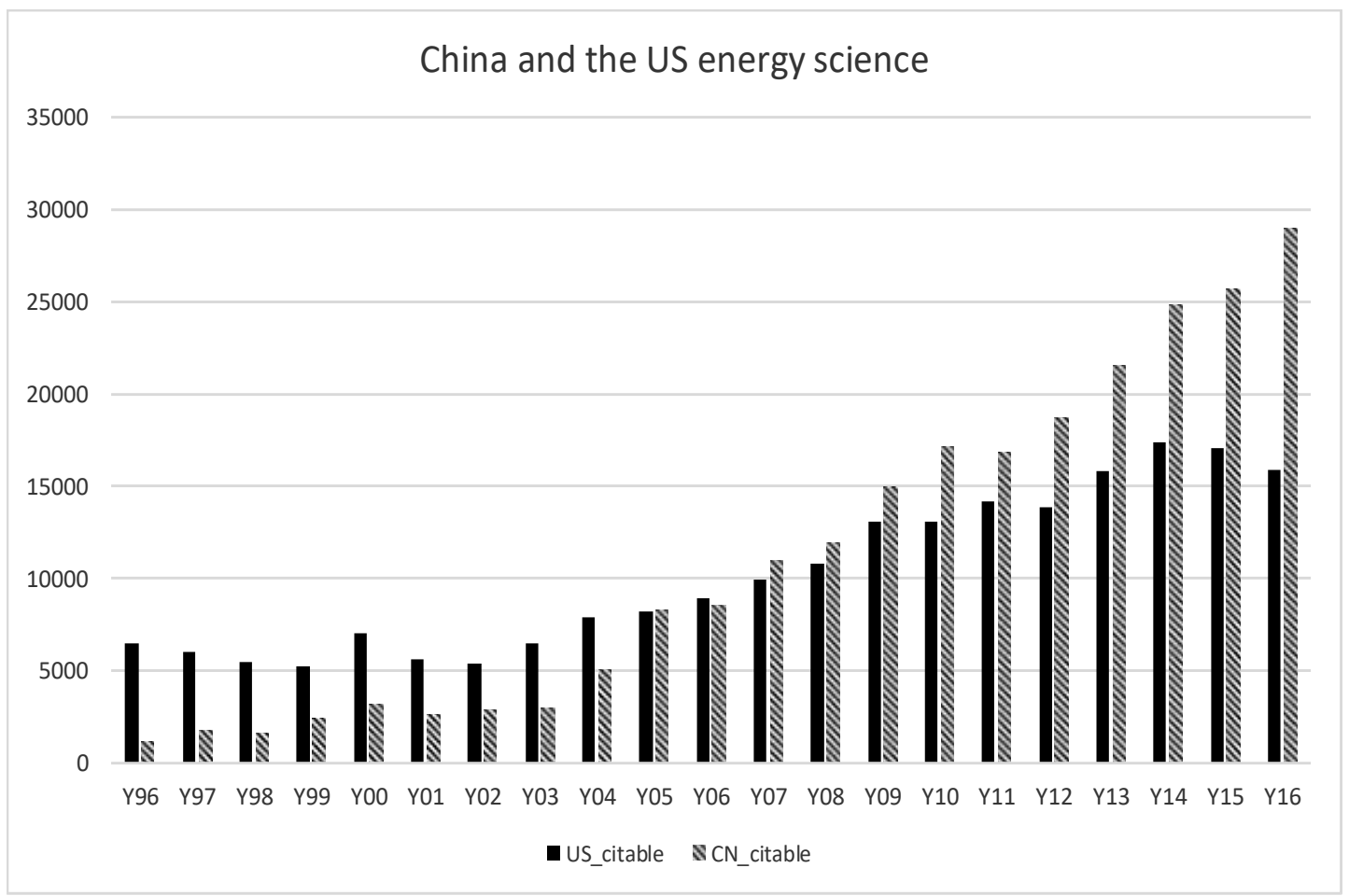


Appendix E: China and the US environment science

China and US enviroment science

35000

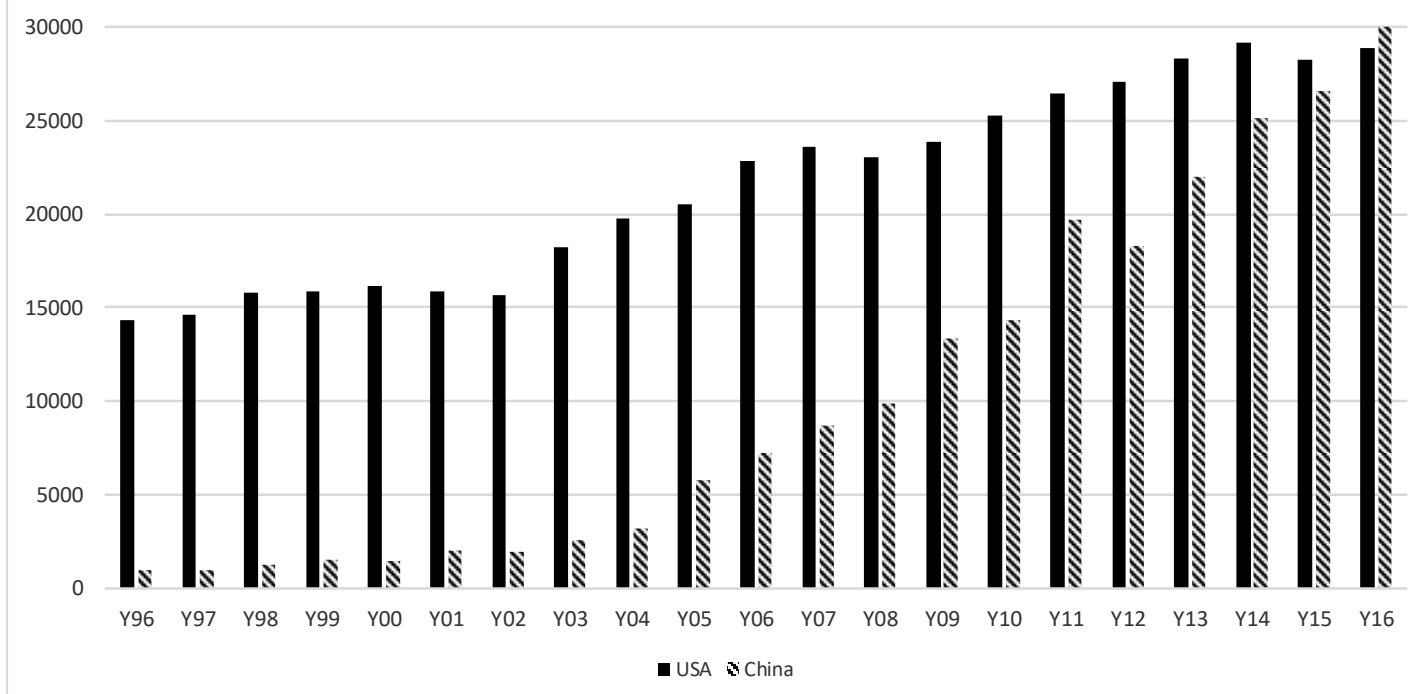


Appendix F: Intra-disciplinary analysis

\begin{tabular}{llll}
\hline Variables & Model 1 & Model 2 & Model 2 \\
\hline Constant & $15.63(.94)^{* * *}$ & $11.9(.90)^{* * *}$ & $11.5(1.1)^{* * *}$ \\
& & & \\
Energy Miscellaneous & & & $-0.83(.16)^{* * *}$ \\
Energy Engineering & $-1.18(.16)^{* * *}$ & & $-0.86(.32)^{* *}$ \\
Energy Fuel Tech & $0.25(.32)$ & & $0.78(.23)^{* * *}$ \\
Nuclear Energy & $0.97(.24)^{* * *}$ & & $0.83(.15)^{* * *}$ \\
Energy Renewable & $0.81(.12)^{* * *}$ & & $-0.65(.25)^{* *}$ \\
& $-.87(.24)^{* * *}$ & & \\
Miscellaneous & & & $0.76(.27)^{* *}$ \\
Ecological Modelling & & $0.37(.28)$ & $-0.55(.21)^{* *}$ \\
Ecology & & $-0.32(.23)$ & $1.65(.30)^{* * *}$ \\
Environmental Chemistry & & $1.03(.30)^{* * *}$ & $2.95(.39)^{* * *}$ \\
Environmental Engineering & & $3.75(.41)^{* * *}$ & $1.12(.32)^{* * *}$ \\
Global and Planetary Change & & $0.73(.32)^{* *}$ & $0.02(.19)$ \\
Health, Toxicology \& Mutagenesis & & $-0.02(.20)$ & $-1.99(.36)^{* * *}$ \\
Management, policy, and law & & $-1.30(.36)^{* * *}$ & $-1.15(.29)^{* * *}$ \\
Nature-Landscape conservation & & $-1.93(.29)^{* * *}$ & $-0.57(.22)^{* *}$ \\
Pollution science & & $-0.11(.22)$ & $-0.08(.48)$ \\
Waste Management and Disposal & & $-0.49(.52)$ & $-0.37(.34)$ \\
Waste Science and Technology & & $-0.53(.36)$ & $-0.88(.31)^{* * *}$ \\
& & $-1.00(.32)^{* * *}$ & \\
F-statistics & & & 0.19 \\
R-square & $144 * * *$ & $262 * * *$ & 17 \\
DOF & & 0.09 & 624 \\
N & 5.20 & 12 & \\
\hline
\end{tabular}


Appendix G: Mediation tests

\begin{tabular}{|c|c|c|}
\hline DOF & Inter-disciplinary association & Size \& significance \\
\hline 1 & Energy $\rightarrow$ Co 2 emission & $.31(.08)^{* * *}$ \\
\hline 1 & Environment $\rightarrow \mathrm{Co} 2$ emission & $.03(.09)^{* * *}$ \\
\hline 1 & Energy $\rightarrow$ Environment & $0.77(.01)^{* * *}$ \\
\hline 1 & Environment $\rightarrow$ Energy & $1.15(.02)^{* * *}$ \\
\hline 2 & $\begin{array}{l}\text { Energy (Environment controlled) } \rightarrow \mathrm{Co} 2 \\
\text { emission }\end{array}$ & $0.68(.22)^{* *}$ \\
\hline 2 & Environment (energy controlled) $\rightarrow \mathrm{Co} 2$ emission & $-0.47(.26) \pm$ \\
\hline 31 & Energy (Environment controlled) $\rightarrow \mathrm{Co} 2$ emission & $-0.01(.28)$ \\
\hline 31 & Environment (energy controlled) $\rightarrow \mathrm{Co} 2$ emission & $-0.93(.29)^{* * *}$ \\
\hline 31 & Interaction (Energy \& environment) & $-0.07(.02)^{* * *}$ \\
\hline $33^{\mathrm{m}}$ & Interaction (Energy \& environment) & $-0.08(.04)^{* *}$ \\
\hline Others ${ }^{\mathrm{c}}$ & Publication citation; Resident-patents & \\
\hline $\begin{array}{l}{ }^{\mathrm{m}} \text { Main ef } \\
{ }^{\mathrm{c}} \text { Separate } \\
* * * \mathrm{p}<.00 \\
* * \mathrm{p}<.01 \\
* \mathrm{p}<.05 \\
\pm \mathrm{p}<.10\end{array}$ & $\begin{array}{l}\text { s not significant } \\
\text { t of environment citation }=\text { negative } \& \text { significant }\end{array}$ & \\
\hline
\end{tabular}


Appendix $\mathrm{H}$ : The composition of $\mathrm{Co} 2$ emission sources Type Sources \& construction

Co2 emissions from manufacturing industries and construction ( $\%$ of total fuel combustion)

Co2 emissions from solid fuel consumption ( $\%$ of total) \& from other sectors
Co2 emissions from manufacturing industries and construction contain the emissions from combustion of fuels in industry. It also includes emissions from industry auto-producers that generate electricity and heat.

Carbon dioxide emissions from solid fuel consumption refer to emissions from the use of coal as an energy source.

$\mathrm{Co} 2$ emissions from other sectors, less residential buildings, and commercial and public services, holds the emissions from commercial/ institutional activities, residential, agriculture/ forestry, fishing, and other emissions.

$\mathrm{Co} 2$ emissions from transport $\mathrm{Co} 2$ emissions from transport contain emissions from the (\% of total fuel combustion) combustion of fuel for all transport activity, regardless of the sector, except for international marine bunkers and international aviation. It includes domestic aviation, domestic navigation, road, rail, and pipeline transport

Co2 emissions from residential $\mathrm{Co} 2$ emissions from residential buildings and commercial and buildings and commercial and public services have all emissions from fuel combustion in public services ( $\%$ of total fuel households. combustion)

Sources: The World Bank (2016)

\footnotetext{
${ }^{\mathrm{i}}$ Energy \& Environment combination AC (++); Energy \& environmental combination BD (- -) constitute the direct analysis. The cross-interaction AD (Energy +)(Environment -) and BC (Energy

-) (Environment + ) test the mediation effects-intra-disciplinary bricolage

ii Negative mediation implies that the positive sign changes to the negative sign.
} 